if the membranes have ruptured prematurely. These are always anxious cases. There may be disproportion or an occipito-posterior position, in both of which cases labour tends to be slow and pains poor. But often neither of these is present and the delay is then generally due to primary uterine inertia. If the membranes are unruptured the long first stage does not matter much, though it tries the patience of all concerned. If the membranes have ruptured prematurely, however, the life of the foetus is then endangered, because as liquor trickles away the uterus is allowed to retract excessively and progressively diminish the area of attachment of the placenta and the foetal and maternal circulation through it. If it proceeds far enough this will cause foetal asphyxia and intrauterine death. These cases can be very anxious ones, and little can be done except to give a sedative, keep the bowels and bladder empty (a warm soap-and-water enema often stimulates strong contractions), and avoid fussy and repeated vaginal examinations. The foetal heart sounds should, of course, be examined at intervals. Most of these labours end spontaneously or the patients are easily and safely delivered by low forceps; but in a few cases anxiety arises because the foetal heart sounds indicate foetal distress before the cervix is fully dilated. The best course to adopt then needs both experience and good judgment. It is often possible to complete the dilatation of the cervix manually and apply forceps, but this is always a hazardous procedure for the child, especially as the dilatation is apt to be imperfect. If the cervix is thinned out over the head it may be divided at 5 and 7 o'clock by scissors after applying the forceps and drawing the head gently downwards. But more and more of these cases are now being treated by lower-segment caesarean section, which is usually much safer for both child and mother.

\section{Constriction Ring}

This is one of the more infrequent causes of failure. It may be the only cause or it may complicate contracted pelvis or unrotated occipito-posterior cases. Usually the head descends fairly well when forceps traction is made, but it quickly recedes again when traction is stopped. This should make one suspicious, but the condition can only be diagnosed by removing the blades, inserting the finger, and feeling the ring as hard as iron around the neck. In such cases the forceps should be reapplied and one capsule ( 3 minims : $0.18 \mathrm{ml}$.) of amyl nitrite crushed on gauze under the patient's nose so that she may inhale it. Relaxation takes place immediately, but is temporary. The forceps should therefore be in place for delivery without unnecessary delay. An alternative method is to inject subcutaneously 7 minims $(0.62 \mathrm{ml}$.) of 1 in 1,000 adrenaline.

Finally, a certain number of failed forceps cases arise through application of the instrument to a hydrocephalic head, an undiagnosed breech, a mento-posterior or brow presentation, or when there is obstruction by a pelvic tumour.

\section{Should the Forceps be Applied or Not?}

On each blade of the forceps there should be a large question mark. On taking up the first blade and seeing the question mark the operator should ask himself, "Are the conditions present that make the application of forceps safe-the membranes ruptured, a vertex presentation with the occiput anterior and the sagittal suture in the anteroposterior diameter, the bladder and bowels empty, the lower pole of the head at least at the level of the ischial spines, the os fully dilated ?" On taking up the second blade he should ask himself, "What are the indications justifying the application of forceps in this case?" Apart from the case when the head is on the perineum, when application of forceps (preferably preceded by episiotomy in a primipara) is always safe, there are only two real indications for forceps-maternal or foetal distress.

Finally, we should all of us keep in mind the words of our master, Smellie. "Students should never think themselves perfect ; for after all the instruction that can possibly be conveyed there are many things in midwifery that can only be learned by practice and observation; and cases will sometimes arise which will puzzle and foil the best practitioners."

\section{BIBLIOGRAPHY}

C.aye, A. M. (1931). Practitioner, 126, 611

Miller, D. (1928). British Medical Journal, 2, 183.

Murray, E. Farquhar (1927). Clinical J., 56, 488

Phillips, L. (1926). Lancet, 1, 113.

Shaw. W. Fletcher (1928). British Medical Journal, 2, 188

Smellie, William (1774). A Collection of Cases and Observations in Midwifery, vol. 3, 6th ed. London.

Stacey, J. ¿. (1931). British Medical Journal, 2, 1073

\section{Preparations and Appliances}

\section{HOSPITAL SYRINGE SERVICE}

Mr. P. G. Merrett, theatre technician, St. Thomas's Hospital. writes: In modern anaesthesia the use of 2-ml. syringes both for immediate and for intermittent use during operations seems tc have increased with the introduction of curare and its antidotes. I thought, therefore, that a method of packing syringes ready for supply at a moment's notice would be acceptable, and have devised the following contrivance, which has met with the approval of most of the anaesthetists at this hospital. The type of sterilization is by dry heat.

As the accompanying diagram shows, the requirements are heat-resistant syringes, oven - glass t u be s, "cellophane," and a small rubber band to seal and secure the end of the tube when ready for sterilizing. Care of the needlepoint is important, and for this purpose use is made of a piece of the brass needleholding tray supplied by most manufacturers with new needles. The unw a n te d clips are

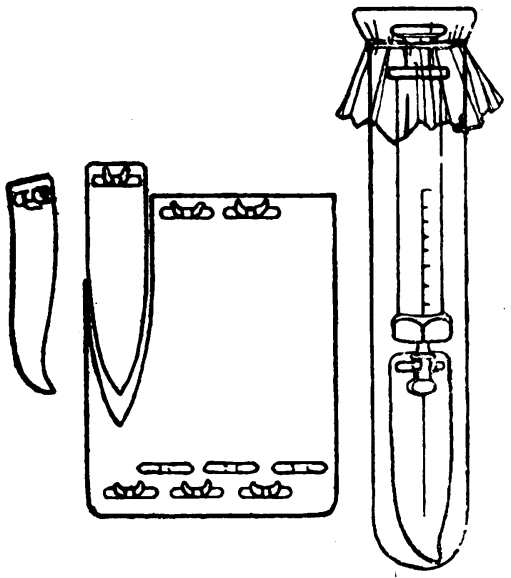

flattened, leaving one for each guard, and cut out as shown. This guard is easily clipped to the needle-butt and hand-shaped so as to be deflected from the point of the needle. The tapered end is curved inwards slightly to fit the bottom of the glass tube, and serves as a protection to the whole. This method has stood up to normal use. If required, an absorbent cotton roll, as used for dental purposes, can be inserted alongside the needle. This provides a swab for cleaning the area of injection, and can be used to protect the needle if the syringe is required for intermittent injection. Most anaesthetic trolleys could carry a small bottle of surgical spirit.

There is no doubt the method could be adapted for other branches of medical, surgical, and laboratory work, and it might be handy in a central supply. depot.

A set of pictures for public display has been prepared on "Coughs and Sneezes" by the Central Office of Information. Local authorities may obtain these sets from the C.O.I. (Room 2301), Block 2, Montagu Mansions, Crawford Street, Baker Street, London, W.1. 